\title{
Splenic infarction, warm autoimmune hemolytic anemia and antiphospholipid antibodies associated with systemic lupus erythematosus
}

\author{
Irfan Yavasoglu • Gurhan Kadikoylu • \\ Zahit Bolaman
}

Received: 8 April 2012/Revised: 11 May 2012/Accepted: 14 May 2012/Published online: 24 May 2012

(c) The Japanese Society of Hematology 2012

\section{Dear Editor}

The article entitled "Splenic infarction, warm autoimmune hemolytic anemia and antiphospholipid antibodies in a patient with infectious mononucleosis" written by Cull et al. [1] and published in one of the recent issues of your journal was quite interesting. We would like to emphasize a number of points with regard to this phenomenon.

Regular, vigilant testing for systemic lupus erythematosus (SLE) is required in patients initially diagnosed with autoimmune hemolytic anemia (AIHA). In patients with SLE and concomitant Coombs-positive AIHA, anticardiolipin antibodies (aCL) are found more frequently and at higher titers than in SLE patients without AIHA [2,3].

Laboratory and imaging findings suggested a diagnosis of antiphospholipid syndrome (APS), an autoimmune disorder characterized by recurrent venous thrombosis or arterial occlusive events and fetal losses associated with elevated levels of aCL. APS may occur in association with SLE in childhood, as well as in adults. Coombs-positive AIHA is also associated with APS [4]. Splenic infarct may be seen in SLE [4].

False-positive findings of heterophile antibodies are more common among persons with connective tissue disease (such as SLE, Sjögren's syndrome), lymphoma, viral hepatitis, and malaria [5].

The most diagnostically important autoantibodies are antinuclear antibodies (ANA), as these test positive in $>95 \%$ of SLE patients, usually at the onset of symptoms.
A few patients develop ANA within 1 year of symptom onset; repeated testing may thus be useful $[3,4]$.

In conclusion, we suggest that it is important to evaluate for both SLE and ANA in female patients presenting with aCL positivity and AIHA.

Conflict of interest We did not receive any financial support. This study has not been published in any journal. We have no conflict of interest.

\section{References}

1. Cull E, Stein BL. Splenic infarction, warm autoimmune hemolytic anemia and antiphospholipid antibodies in a patient with infectious mononucleosis. Int J Hematol. 2012;95(5):573-6.

2. Baek SW, Lee MW, Ryu HW, Lee KS, Song IC, Lee HJ, et al. Clinical features and outcomes of autoimmune hemolytic anemia: a retrospective analysis of 32 cases. Korean J Hematol. 2011; 46(2):111-7.

3. Lang B, Straub RH, Weber S, Röther E, Fleck M, Peter HH. Elevated anticardiolipin antibodies in autoimmune haemolytic anaemia irrespective of underlying systemic lupus erythematosus. Lupus. 1997;6(8):652-5.

4. Constantin T, Ponyi A, Varga E, Danko K, Fekete G, Kovacs G. Antiphospholipid syndrome accompanied by a silent splenic infarct in a patient with juvenile SLE. Rheumatol Int. 2006;26(10): 951-2.

5. Berkun Y, Zandman-Goddard G, Barzilai O, Boaz M, Sherer Y, Larida $\mathrm{B}$, et al. Infectious antibodies in systemic lupus erythematosus patients. Lupus. 2009;18(13):1129-35.
I. Yavasoglu $(\bowtie) \cdot$ G. Kadikoylu $\cdot$ Z. Bolaman

Division of Hematology, Adnan Menderes University Medical

Faculty, 09100 Aydin, Turkey

e-mail: dr_yavas@yahoo.com 